\title{
Efficacy of ipamorelin, a ghrelin mimetic, on gastric dysmotility in a rodent model of postoperative ileus
}

This article was published in the following Dove Press journal:

Journal of Experimental Pharmacology

19 October 2012

Number of times this article has been viewed

\author{
Beverley Greenwood-Van \\ Meerveld ${ }^{1-3}$ \\ Karl Tyler ${ }^{3}$ \\ Ehsan Mohammadi ${ }^{3}$ \\ Claudio Pietra ${ }^{4}$ \\ 'VA Medical Center, ${ }^{2}$ Department \\ of Physiology, ${ }^{3}$ Oklahoma Center \\ for Neuroscience, University of \\ Oklahoma Health Science Center, \\ Oklahoma City, OK, USA; ${ }^{4}$ Helsinn \\ Healthcare SA, Lugano, Switzerland
}

Correspondence: Beverley GreenwoodVan Meerveld

University of Oklahoma Health Sciences

Center, Stanton L Young Biomedical

Research Center, 975 NE I0th Street,

BRC 272, Oklahoma City, OK 73104, USA

Tel + I 40527 I 6267

Fax +l 405 27| 3552

Email beverley-greenwood@ouhsc.edu
Background: Delayed gastric emptying is a common disorder with few effective therapeutic options. The goal of this study was to investigate whether ipamorelin, a synthetic peptidomimetic that acts on the ghrelin receptor, accelerates gastric emptying in a rodent model of gastroparesis induced by abdominal surgery and intestinal manipulation.

Methods: Fasted adult male rats were subjected to laparotomy and intestinal manipulation. Following the surgery rats received ipamorelin $(0.014-0.14 \mu \mathrm{mol} / \mathrm{kg})$ or vehicle control via intravenous administration. Gastric emptying was measured by the percent of total recovered radioactivity remaining in the stomach 15 minutes after intragastric gavage of $1.5 \mathrm{~mL}$ of ${ }^{99 \mathrm{~m}} \mathrm{Tc}$ (technicium-99m) sulfur colloid in $0.5 \%$ methylcellulose. In a separate group of rats subjected to laparotomy and intestinal manipulation, the gastric fundus was isolated and tissue segments were suspended in an organ bath to assess the effect of ipamorelin $(1 \mu \mathrm{M})$ on gastric smooth muscle contractility induced by acetylcholine and electrical field stimulation.

Results: Abdominal surgery caused a delay in gastric emptying with $78 \% \pm 5 \%$ of the meal remaining in the stomach in vehicle controls. Ipamorelin $(0.014 \mu \mathrm{mol} / \mathrm{kg}$ intravenous $)$ resulted in a significant acceleration ( $P<0.05$ vs vehicle-treated rat) of gastric emptying with $52 \% \pm 11 \%$ of the meal remaining in the stomach compared to nonsurgical control animals with $44 \% \pm 6 \%$. Following abdominal surgery and intestinal manipulation, isolated preparations of gastric smooth muscle exhibited a marked inhibition of acetylcholine and electrical field stimulation-induced contractile responses, which were reversed by ipamorelin and ghrelin.

Conclusion: These results suggest that ipamorelin accelerates gastric emptying in a rodent model of postoperative ileus through the stimulation of gastric contractility by activating a ghrelin receptor-mediated mechanism involving cholinergic excitatory neurons.

Keywords: gastroparesis, ipamorelin, rat, stomach

\section{Introduction}

Postoperative ileus (POI) is a transient loss of gastrointestinal (GI) motility that occurs following abdominal surgery or other major surgical procedures. Symptoms of POI include abdominal distention, nausea, vomiting, anorexia, and constipation, which can lead to prolonged hospitalization and potentially serious complications. ${ }^{1}$ The mechanisms causing POI are complex, involving immune and neuronal responses resulting in delayed gastric emptying and impaired propulsive motility of the bowel. ${ }^{2,3}$ In addition, opioid drugs used for pain management contribute significantly to delayed GI transit following abdominal surgery. ${ }^{4}$

Ghrelin is an important orexigenic peptide that exerts gastroprokinetic effects and represents a novel therapeutic approach for treating GI motility disorders. ${ }^{5-7}$ 
Recently, a number of agents that mimic the activity of endogenous ghrelin have been proposed as treatments of POI. For example, TZP-101, a small molecule with potent binding affinity and full agonist activity at the human recombinant ghrelin receptor (GRLN-R), is now in clinical development for the treatment of gastroparesis and associated symptoms. ${ }^{8-10}$ GRLN-R has been previously identified as an orphan receptor referred to as the growth hormone releasing peptide (GHRP)-receptor or growth hormone secretagogue receptor because its activation by synthetic small peptide compounds resulted in the release of growth hormone from the pituitary gland. ${ }^{11}$ The GI prokinetic effects of ghrelin mimetics have been demonstrated in experimental models and humans. ${ }^{12,13}$ Additionally, in ex vivo models, ghrelin and other ghrelin mimetics have been shown to stimulate smooth muscle contractility in multiple isolated GI preparations. ${ }^{14-16}$

In a rodent model of POI, we previously found that ipamorelin, which selectively stimulates GRLN-R without significantly affecting plasma adrenocorticotropic hormone and cortisol levels, ${ }^{17}$ caused a dose-dependent decrease in the time to the first bowel movement and increases in cumulative fecal pellet output following abdominal surgery. ${ }^{18}$ Although ipamorelin was shown to have these effects in the lower GI tract, the effect of the compound on more proximal regions of the GI tract are unknown. Therefore, the goal of the current study was to investigate whether ipamorelin affects the upper GI tract. Specifically, we examined whether the compound accelerates gastric emptying in a rodent model of gastroparesis induced by abdominal surgery and intestinal manipulation. We also aimed to investigate potential mechanisms by which ipamorelin can normalize the contractility of GI smooth muscle. Currently, both central and peripheral mechanisms are thought to be involved in the stimulation of GI motility by ghrelin and ghrelin mimetics. Central vagovagal reflex pathways likely play an important role in the promotility effects of ghrelin; ${ }^{19-22}$ a recent study proposed that down-regulation of the ghrelin receptor may account for delayed intestinal transit following vagotomy. ${ }^{23}$ The prokinetic effects of ghrelin may also involve activation of the enteric nervous system. To support a peripheral neural mechanism, studies have identified ghrelin receptors on enteric neurons. ${ }^{24}$ Moreover, in isolated smooth muscle from the rat fundus, ghrelin agonists decreased the "on" relaxation and enhanced a cholinergically mediated "off" contraction that had been previously unmasked by the addition of a nitric oxide synthase blocker, L-N (G) Nitroarginine methyl ester (L-NAME). ${ }^{14,15}$ Taken together, these observations suggest that, at a peripheral level, ghrelin interacts in the stomach with cholinergic and nitrergic neurons to enhance gastric smooth muscle contractility and stimulate GI transit.

\section{Materials and methods}

\section{Animals}

Experiments were performed using adult male SpragueDawley rats (225-275 g) obtained from Charles River (Wilmington, MA). The animals were purchased with indwelling catheters implanted in the right jugular vein for administration of drugs or vehicle. To prevent blockage, the catheters were gently flushed with $0.5 \mathrm{~mL}$ heparinized saline every 3-4 days. An acclimation period of at least 1 week was allowed prior to the experiments. All rats were singlehoused with free access to food and water at $21^{\circ} \mathrm{C}-23^{\circ} \mathrm{C}$ and a 12-hour light/dark cycle. The experimental protocol was approved by the Institutional Animal Care and Use Committee (IACUC) at the University of Oklahoma Health Sciences Center (IACUC protocol \# 09-046-H).

\section{Abdominal surgery and intestinal manipulation}

POI was induced by a surgical procedure described as "running of the bowel." ${ }^{25}$ Rats were fasted overnight (1618 hours), anesthetized with isoflurane ( $2 \%-5 \%$ to effect), the abdomen was shaved, and the area was treated with alcohol followed by Betadine ${ }^{\circledR}$ (povidone-iodine ; Webster Vet Supplies Inc., Bessemer, AL) for disinfection, and a midline incision was made to expose the viscera. Running of the bowel was performed using two saline-soaked cotton-tipped applicators and gently massaging the bowel (stomach to distal colon) for 5 minutes. Upon completion of this procedure, the GI organs were covered with saline-soaked gauze for an additional 10 minutes. At the end of the surgery, the small intestine and the cecum were returned to the abdominal cavity and the incision was closed with running silk sutures. The surgical procedure lasted 25-30 minutes and was performed between 7 and 9 am.

\section{Evaluation of gastric emptying and intestinal transit}

Conscious rats received an intragastric gavage of $1.5 \mathrm{~mL}$ of ${ }^{99 \mathrm{~m}} \mathrm{Tc}$ in $1.5 \%$ methylcellulose solution in distilled water. ${ }^{99 \mathrm{~m}} \mathrm{Tc}$ radioactivity was adjusted to approximately 100,000 counts per minute (cpm). Having received the radioactive meal, the animals were placed in a wire-bottom cage without access to food or water. After 15 minutes the animals were euthanized by $\mathrm{CO}_{2}$ inhalation, the abdomen was opened, 
and the stomach was clamped using a single silk ligature at the esophageal junction and two parallel ligatures between the pyloric junction and the duodenum. The stomach was isolated and gastric emptying was assessed via the amount of radioactivity remaining in the stomach. Sections of the small intestine, each $10 \mathrm{~cm}$ in length, were separated, and transit was assessed by the geometric center calculated as a function of the amount of radioactivity in each intestinal segment. The geometric center $=\sum(\%$ of total radioactivity per segment $\times$ number of segment)/100 with a geometric center of 1 representing the duodenum, 2-8 the jejunum, and $>8$ the ileum. The distance traveled by the head of the radiolabeled meal along the length of the small intestine was also determined as previously described. ${ }^{25,26}$

\section{Evaluation of gastric muscle contractility}

Circular muscle strips with the mucosa removed were isolated from the gastric fundus taken from normal controls and POI rats. Muscle strips were suspended vertically in organ baths (Radnoti Glass Technology Inc, Monrovia, CA) under optimal stretch $(0.75 \mathrm{~g})$, and isometric contractile activity was recorded using a force transducer attached to a MacLab Data Acquisition System (ADInstruments Inc, Colorado Spring, CO). The organ bath contained warmed and oxygenated $\left(37^{\circ} \mathrm{C}\right) \mathrm{Krebs}$ solution with the following composition: $\mathrm{NaCl}(120 \mathrm{mM}), \mathrm{KCl}(6 \mathrm{mM})$, $\mathrm{MgCl}_{2}(1.2 \mathrm{mM}), \mathrm{NaH}_{2} \mathrm{PO}_{4}(1.2 \mathrm{mM}), \mathrm{CaCl}_{2}(2.5 \mathrm{mM})$, $\mathrm{NaHCO}_{3}(14.4 \mathrm{mM})$, and glucose $(11.5 \mathrm{mM})$. After 1 hour of equilibration, the contractile responses to acetylcholine $(\mathrm{ACh} ; 100 \mu \mathrm{M})$ and electrical field stimulation (EFS: $0.5 \mathrm{~ms}$ pulse duration, 5-32 Hz, $1 \mathrm{~ms}$ pulse duration applied at $10 \mathrm{~s}$ interval at $6 \mathrm{~V}$ ) were assessed before and following ipamorelin $(1 \mu \mathrm{M})$, ghrelin $(1 \mu \mathrm{M})$, or the vehicle control administration. The concentration of $1 \mu \mathrm{M}$ was selected based on a previous in vitro study with ipamorelin ${ }^{17}$ and upon previous studies in which the efficacy of ipamorelin was found to be similar to that of GHRP. ${ }^{17,18}$ In separate experiments, atropine $(1 \mu \mathrm{M})$ and tetrodoxin (TTX, $1 \mu \mathrm{M}$ ) were used to block the contractile effects of ACh and EFS, respectively.

\section{Test and control articles}

The test compound, ipamorelin free-base (lot \#514356; Albany Molecular Research, Inc, Albany, NY) was provided by Helsinn Healthcare, Inc (Bridgewater, NJ). Since the solubility of ipamorelin is very low, 2 molar equivalents of glacial acetic acid are required to produce a soluble ipamorelin. Stock solutions of $0.5 \mathrm{mg} / \mathrm{mL}$ were prepared daily in sterile saline plus glacial acetic acid $(0.1 \mu \mathrm{L} / \mathrm{mL})$ to bring ipamorelin into solution $(\mathrm{pH} \mathrm{3-4).} \mathrm{The} \mathrm{solution}$ was titrated with $\mathrm{NaOH}$ to $\mathrm{pH}$ 7.0-7.2. Additional dilutions were made in saline. Sterile saline was used in the vehicle control experiments. The ghrelin agonist [D-Lys ${ }^{3}$ ]-GHRP-6, atropine, and TTX were purchased from Sigma-Aldrich (St Louis, MO) and dissolved in saline.

\section{Experimental design and protocol}

Following an overnight fast, the rats were anesthetized and subjected to a laporotomy and manipulation of the bowel surgically that was timed to last 30 minutes. Experiments to evaluate the ability of ipamorelin to reverse the effects of abdominal surgery and intestinal manipulation involved a single administration of the compound. The doses of ipamorelin $(0.014$ and $0.14 \mu \mathrm{mol} / \mathrm{kg})$ were selected based upon data obtained in the same experimental model and to explore a wide dose range. ${ }^{18}$ Both the test and vehicle control were administered as a bolus iv infusion at a volume of $0.2 \mathrm{~mL} / 100 \mathrm{~g}$ body weight via the jugular catheter and immediately followed by the intragastric gavage of $1.5 \mathrm{~mL}$ ${ }^{99 m}$ Tc-labeled methylcellulose meal. The rats were then placed in clean wire-bottom cages (no food or water was supplied) and euthanized via $\mathrm{CO}_{2}$ inhalation 15 minutes after the oral gavage. For the in vivo studies, the stomach and small intestine were isolated for measurement of GI transit. For the in vitro studies, the gastric fundus was isolated and placed in organ baths to record smooth muscle contractility.

\section{Data and statistical analysis}

The data are expressed as the mean \pm standard error of the mean for each group. Differences between groups were assessed for statistical significance by Student's $t$-test, as well as by oneway or two-way analysis of variance followed by Bonferroni's test for multiple comparisons where appropriate. A level of $P<0.05$ was considered significant. The statistical procedures were performed using GraphPad Prism Version 4 software (GraphPad Software Inc, San Diego, CA).

\section{Results \\ Effect of ipamorelin on delayed gastric emptying in vivo}

Figure 1A shows that, in a rodent model of POI, induced by abdominal surgery and manipulation of the bowel, gastric empting was significantly delayed. Specifically, we found that, compared to non-POI surgery controls $(n=10)$, "running of the bowel" induced a postsurgical delay in gastric emptying in vehicle-treated rats $(n=10)$, as measured by the increase in the amount of radioactivity remaining in the stomach. We then investigated the effect of ipamorelin administered 

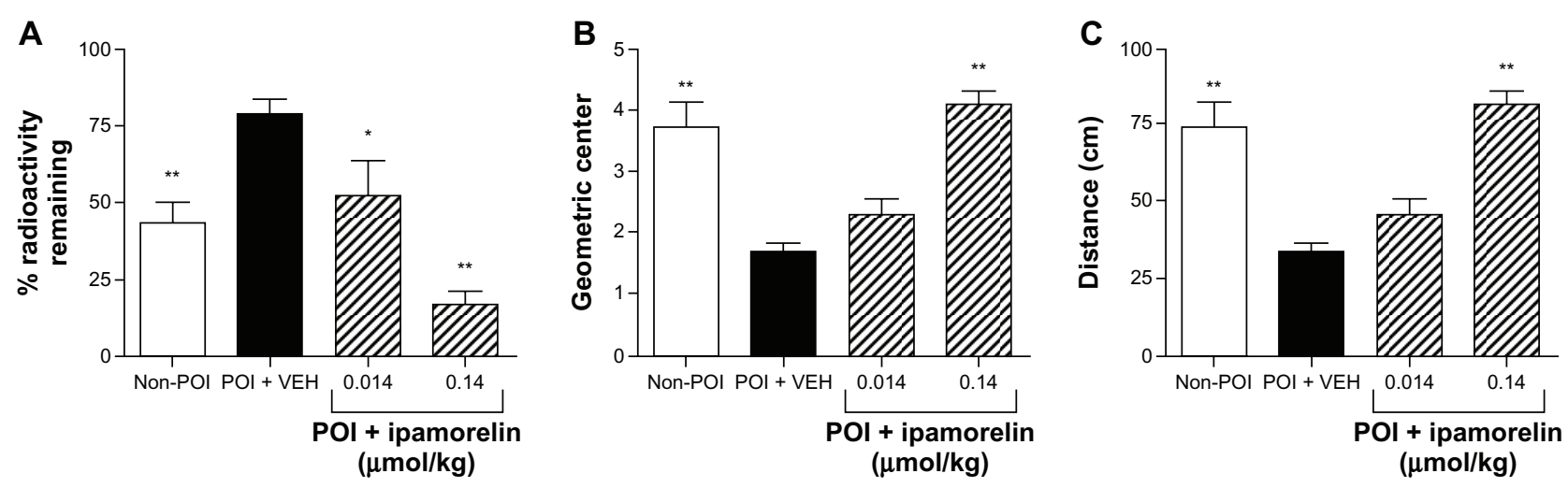

Figure I Effect of ipamorelin in a rat model of POI. Compared to non-POI control rats, abdominal surgery in VEH-treated rats increased the amount of radioactivity remaining in the stomach, decreased the geometric center, and decreased the distance traveled by the head of the radiolabeled meal. Ipamorelin administered intravenously decreased the amount of radioactivity remaining in the stomach $(\mathbf{A})$, increased the geometric center (B), and increased distance traveled by the head of meal (C).

Notes: Data are mean \pm SEM for 5-10 rats in each group. Statistical significance was assessed by one-way analysis of variance followed by Dunnett posttest for multiple comparisons. $* P<0.05 ; * * P<0.01$ compared to POI+VEH-treated rats.

Abbreviations: $\mathrm{POI}$, postoperative ileus; $\mathrm{VEH}$, vehicle.

intravenously at doses of 0.014 and $0.14 \mu \mathrm{mol} / \mathrm{kg}$ on the delay in gastric emptying produced by abdominal surgery and intestinal manipulation. As illustrated in Figure 1A, ipamorelin $(0.014 \mu \mathrm{mol} / \mathrm{kg}$ iv, $\mathrm{n}=5)$ decreased the amount of radioactivity remaining in the stomach to a level resembling the non-POI surgery control rats. The higher dose of ipamorelin $(0.14 \mu \mathrm{mol} / \mathrm{kg}$ iv, $\mathrm{n}=8)$ had a greater effect on the delay in gastric emptying induced by POI with less than $25 \%$ of the radioactivity remaining in the stomach after 15 minutes.

\section{Effect of ipamorelin on intestinal transit in vivo}

In the current study, we investigated the effect of ipamorelin on small intestinal transit in vivo. We found that in the nonPOI controls the majority of the test meal traveled to the distal small intestine, whereas following abdominal surgery and intestinal manipulation, most of the test meal remained in the proximal small intestine. Specifically in vehicle-treated rats, POI caused a significant slowing of small intestinal transit as assessed as demonstrated by a decrease in the geometric center (Figure 1B) and a decrease in the distance traveled along the small intestine by the head of the meal compared to nonsurgery controls (Figure 1C). In rats treated with the highest dose of ipamorelin $(0.14 \mu \mathrm{mol} / \mathrm{kg}$ iv $)$, there was a reversal of the POI-induced delay in upper GI transit to values that resembled non-POI surgery controls (Figure 1B and C).

\section{Effects of ipamorelin on contractility in vitro}

After demonstrating that ipamorelin reverses the delay in gastric emptying induced by abdominal surgery and intestinal manipulation in vivo, we designed a series of in vitro experiments using tissue isolated from the gastric fundus to investigate the potential mechanisms by which ipamorelin accelerates gastric emptying. As shown in Figure 2, we found that following abdominal surgery and intestinal
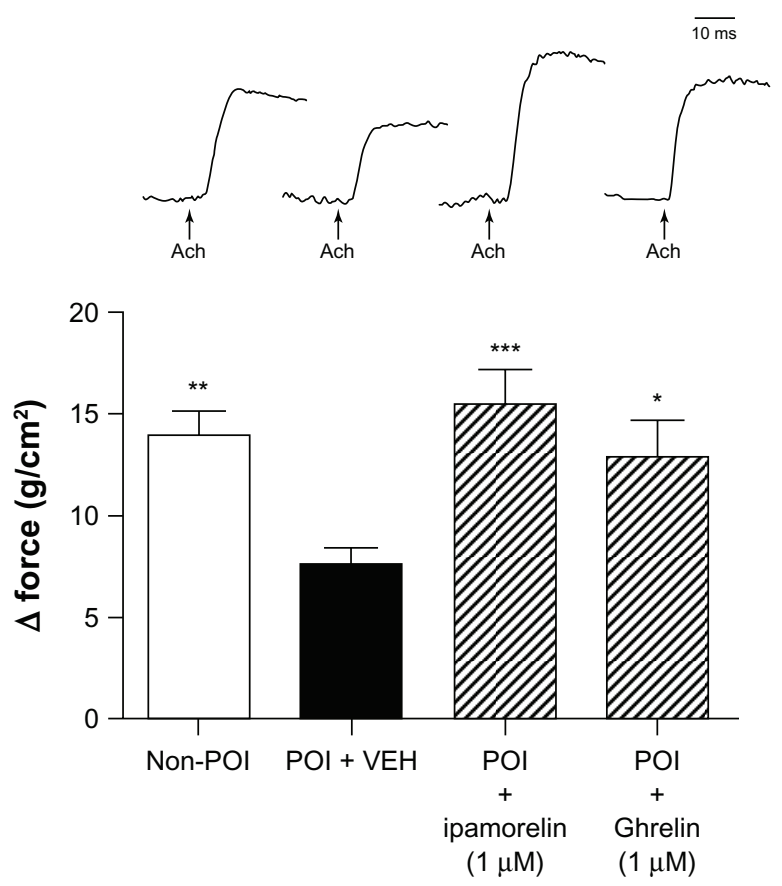

Figure 2 Effect of ipamorelin $(I \mu \mathrm{M})$ and ghrelin $(I \mu \mathrm{M})$ on gastric smooth muscle contractility induced by $\mathrm{ACh}$ at $100 \mu \mathrm{M}$ isolated from a rat model of POI.

Notes: Traces above the histogram represent the contractile response to ACh. Compared to non-POI controls, POI in VEH-treated rats inhibited gastric smooth muscle contractility induced by ACh. Ipamorelin and ghrelin normalized the contractile response to $\mathrm{ACh}$. Data are mean \pm SEM for 10 to $1 \mathrm{I}$ experiments in each group. Statistical significance was assessed by one-way analysis of variance with Bonferroni posttest comparisons. $* P<0.05$; $* * P<0.01$; $* * * P<0.001$ compared to POI+VEH-treated tissue.

Abbreviations: $\mathrm{ACh}$, acetylcholine; $\mathrm{POI}$, postoperative ileus; $\mathrm{VEH}$, vehicle. 
manipulation, there was a marked inhibition of the smooth muscle contractile responses to cholinergic stimulation with $\mathrm{ACh}$ at $100 \mu \mathrm{M}$ compared to that observed in isolated gastric fundic smooth muscle preparations from nonsurgery control rats. The ACh-induced contractile response was completely antagonized by the muscarinic antagonist, $1 \mu \mathrm{M}$ atropine (data not shown). Figure 2 shows that, in the gastric fundus isolated from rats with POI, both ipamorelin and ghrelin normalized the contractile response to $\mathrm{ACh}$. We also found that the neurally mediated contractile responses induced by EFS of the enteric nerves within the gastric fundus were significantly inhibited in POI rats compared to nonsurgery controls (Figure 3). These neurally induced contractile responses were completely blocked by the addition of TTX $(1 \mu \mathrm{M})$, a potent neurotoxin that binds to voltage-gated fast $\mathrm{Na}^{+}$channels in nerve membranes (data not shown). Figure 3 also shows that, in the gastric fundus isolated from rats with POI, both ipamorelin and ghrelin normalized the contractile response to EFS.

\section{Discussion}

Delayed gastric emptying, also known as gastroparesis or gastric stasis, occurs when the coordinated motility of the stomach is dysregulated and food is retained in the stomach, leading to symptoms of early satiety, nausea, vomiting, and abdominal pain. Based on the vast body of literature published on the prokinetic effects of ghrelin mimetics, ${ }^{18,26,27}$ the aim of the current study was to investigate whether ipamorelin, a synthetic ghrelin mimetic that has specific growth hormone-releasing properties but does not increase plasma levels of adrenocorticotropic hormone or cortisol, ${ }^{17,28}$ has effects on upper GI tract dysmotility using a rodent model of
POI transit induced by abdominal surgery and manipulation of the bowel..$^{25}$ The rat model of POI is commonly used to investigate the efficacy of new therapeutic treatments as well as the pathogenic mechanisms relevant to the postsurgical development of GI dysfunction in humans. Analysis of our data confirmed that abdominal surgery and manipulation of the bowel caused a marked delay in gastric emptying and upper GI transit in a rodent model. One of the major results in this study was the finding that administration of ipamorelin resulted in a significant acceleration of the test meal leaving the stomach, with the level of gastric emptying produced by ipamorelin virtually identical to that measured in non-surgical control animals. Similarly, prokinetic effects of ipamorelin were also observed in the small rat intestine. Following abdominal surgery and intestinal manipulation, intravenous administration of ipamorelin increased the geometric center and the distance traveled by the radiolabeled test meal along the length of the small intestine.

Our in vivo findings are consistent with those of previous studies in conscious rats where ghrelin, GHRP-6, and a series of small molecule synthetic selective ghrelin receptor agonists, accelerated gastric empting and enhanced small bowel transit in a rodent model of POI. ${ }^{14,26,29}$ Moreover, these findings with ipamorelin extend the results of our previous studies, which demonstrated that ipamorelin after single and repeated administration reduces the time to first bowel movement in a rodent model of delayed GI transit. ${ }^{18}$ Since our current results suggest that ipamorelin accelerates gastric emptying and promotes small intestinal function, our findings support the feasibility and potential benefits of using GRLN-R agonists as a new class of prokinetics accelerating gastric emptying. Furthermore, taken together with

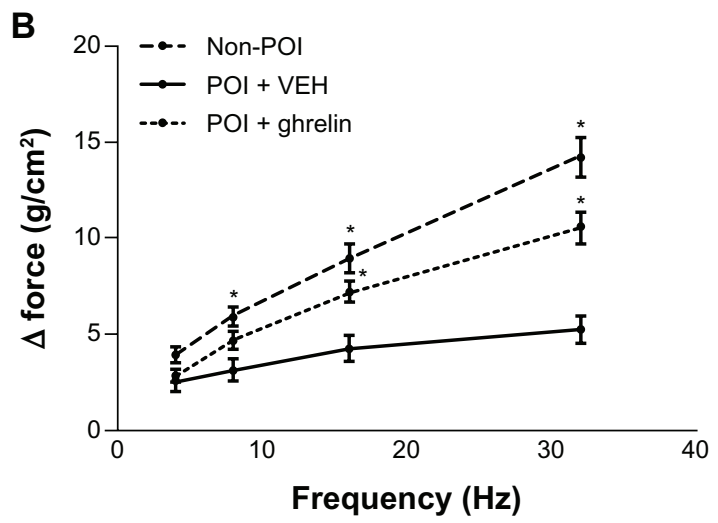

Figure 3 Effect of ipamorelin $(I \mu M)(A)$ and ghrelin $(I \mu M)(B)$ on gastric smooth muscle contractility induced by EFS in a rat model of POI.

Notes: In gastric smooth muscle isolated from POI+VEH-treated rats, there was an inhibition of gastric smooth muscle contractility induced by EFS compared to nonsurgery controls. Ipamorelin and ghrelin normalized the contractile response to EFS. Data are mean \pm SEM for 10 to II experiments in each group. Statistical significance was assessed by one-way analysis of variance with Bonferroni posttest comparisons. $* P<0.05$ compared to POI-VEH.

Abbreviations: EFS, electrical field stimulation; POI, postoperative ileus; VEH, vehicle. 
our previous observation that ipamorelin enhances colonic motility, our results suggest that this compound may possess a therapeutic advantage relevant to the pathophysiological heterogeneity of the patient population.

In the current study, we attempted to elucidate the mechanism(s) responsible for the prokinetic effects of ipamorelin. Specifically, we focused our investigation on the mechanisms by which ipamorelin accelerates gastric emptying in a rodent model of POI. In isolated preparations of gastric smooth muscle from rats that had undergone abdominal surgery and manipulation of the bowel, we examined the contractility of the muscle in response to cholinergic stimulation and electrical stimulation of the myenteric plexus. Following abdominal surgery and manipulation of the bowel, there was a marked inhibition of the smooth muscle contractile responses in tissue isolated from the gastric fundus in response to ACh and EFS compared to control tissue. The ACh-induced contractile response was found to be atropinesensitive whereas the increase in contractility to EFS was sensitive to neuronal blockade with TTX, suggesting a neuronal origin for this response. In addition to demonstrating that POI leads to marked abnormalities not only in vivo but also in isolated smooth muscle contractility, another major finding of our study was that ipamorelin normalized the contractile response to ACh and EFS in the gastric fundus. Additionally, we found that the effects of ipamorelin on smooth muscle contractility were mimicked by ghrelin, suggesting that ipamorelin, a potent ghrelin agonist, is effective in an experimental model of delayed gastric emptying by stimulating motility in the stomach though GRLN-receptor mediated mechanisms located on cholinergic neurons.

Immune-mediated mechanisms have also been shown to play a pivotal role in the development of ileus, ${ }^{2,3}$ and a compound with prokinetic ability and anti-inflammatory effects may prove useful for the treatment of POI. Although not investigated in the current study, the possibility exists that ipamorelin, in addition to acting as a gastroproketic, may also possess anti-inflammatory effects. In support of this claim, recent studies in lipopolysaccharide-treated mice found that ghrelin inhibited lipopolysaccharide-induced inducible nitric oxide synthase expression in the GI tract and lowered overproduction of $\mathrm{NO}$ in the plasma, suggesting that ghrelin may downregulate the NO pathway in the GI tract to improve small intestinal transit. ${ }^{31}$

In summary, we have shown for the first time in vivo that ipamorelin significantly accelerates gastric emptying in a rodent model of gastroparesis induced by abdominal surgery. In tissue isolated from the gastric fundus, ipamorelin normalized the contractile response to cholinergic neural stimulation. These results suggest that ipamorelin improves delayed gastric emptying by stimulating gastric contractility via GRLN receptor-mediated mechanisms located on cholinergic neurons. In conclusion, our study highlights the profound effects of ipamorelin on the upper GI tract and suggests that the compound may be of interest as a prokinetic agent to treat GI dysmotility, characterized by delayed gastric emptying and slow upper GI transit.

\section{Disclosure}

The authors report no conflicts of interest in this work.

\section{References}

1. Senagore AJ. Pathogenesis and clinical and economic consequences of postoperative ileus. Am J Health Syst Pharm. 2007;64(20 Suppl 13): S3-S7.

2. de Jonge WJ, van den Wijngaard RM, et al. Postoperative ileus is maintained by intestinal immune infiltrates that activate inhibitory neural pathways in mice. Gastroenterology. 2003;125(4):1137-1147.

3. Bauer AJ, Boeckxstaens GE. Mechanisms of postoperative ileus. Neurogastroenterol Motil. 2004;16 Suppl 2:54-60.

4. Greenwood-Van Meerveld B. Emerging drugs for postoperative ileus. Expert Opin Emerg Drugs. 2007;12(4):619-626.

5. Charoenthongtrakul S, Giuliana D, Longo KA, et al. Enhanced gastrointestinal motility with orally active ghrelin receptor agonists. J Pharmacol Exp Ther. 2009;329(3):1178-1186.

6. De Smet B, Mitselos A, Depoortere I. Motilin and ghrelin as prokinetic drug targets. Pharm Ther. 2009;123(2):207-233.

7. Greenwood-Van MeerveldB, Kriegsman M, Nelson R. Ghrelin as a target for gastrointestinal motility disorders. Peptides. 2011;32(11):2352-2356.

8. Lasseter KC, Shaughnessy L, Cummings D, et al. Ghrelin agonist (TZP-101): safety, pharmacokinetics and pharmacodynamic evaluation in healthy volunteers: a phase I, first-in-human study. J Clin Pharmacol. 2008;48(2):193-202.

9. Ejskjaer N, Dimcevski G, Wo J, et al. Safety and efficacy of ghrelin agonist TZP-101 in relieving symptoms in patients with diabetic gastroparesis: a randomized, placebo-controlled study. Neurogastroenterol Motil. 2010;22(10):1069-e281.

10. Wo JM, Ejskjaer N, Hellstrom PM, et al. Randomised clinical trial: ghrelin agonist TZP-101 relieves gastroparesis associated with severe nausea and vomiting - randomized clinical study subset data. Aliment Pharmacol Ther. 2011;33(6):679-688.

11. Davenport AP, Bonner TI, Foord SM, et al. International Union of Pharmacology. LVI. Ghrelin receptor nomenclature, distribution, and function. Pharmacol Rev. 2005;57(4):541-546.

12. Ariga H, Tsukamoto K, Chen C, Mantyh C, Pappas TN, Takahashi T. Endogenous acyl ghrelin is involved in mediating spontaneous phase IIIlike contractions of the rat stomach. Neurogastroenterol Motil. 2007;19(8):675-680.

13. Tack J, Depoortere I, Bisschops R, et al. Influence of ghrelin on interdigestive gastrointestinal motility in humans. Gut. 2006;55(3):327-333.

14. Depoortere I, De Winter B, Thijs T, De Man J, Pelckmans P, Peeters T. Comparison of the gastroprokinetic effects of ghrelin, GHRP-6 and motilin in rats in vivo and in vitro. Eur J Pharmacol. 2005;515(1-3): $160-168$.

15. Kitazawa T, De Smet B, Verbeke K, Depoortere I, Peeters TL. Gastric motor effects of peptide and non-peptide ghrelin agonists in mice in vivo and in vitro. Gut. 2005;54(8):1078-1084.

16. Xu L, Depoortere I, Tomasetto C, et al. Evidence for the presence of motilin, ghrelin, and the motilin and ghrelin receptor in neurons of the myenteric plexus. Regul Pept. 2005;124(1-3):119-125. 
17. Raun K, Hansen BS, Johansen NL, et al. Ipamorelin, the first selective growth hormone secretagogue. Eur J Endocrinol. 1998;139(5): 552-561.

18. Venkova K, Mann W, Nelson R, Greenwood-Van Meerveld B. Efficacy of ipamorelin, a novel ghrelin mimetic, in a rodent model of postoperative ileus. J Pharmacol Exp Ther. 2009;329(3):1110-1116.

19. Masuda Y, Tanaka T, Inomata N, et al. Ghrelin stimulates gastric acid secretion and motility in rats. Biochem Biophys Res Commun. 2000;276(3): 905-908.

20. Fujino K, Inui A, Asakawa A, Kihara N, Fujimura M, Fujimiya M. Ghrelin induces fasted motor activity of the gastrointestinal tract in conscious fed rats. J Physiol. 2003;550(Pt 1):227-240.

21. Sakata I, Yamazaki M, Inoue K, Hayashi Y, Kangawa K, Sakai T. Growth hormone secretagogue receptor expression in the cells of the stomach-projected afferent nerve in the rat nodose ganglion. Neurosci Lett. 2003;342(3):183-186.

22. Nakamura T, Onage T, Kitizawa T. Ghrelin stimulates gastric motility of the guinea pig through activation of capsaicin-sensitive neural pathway: in vivo and in vitro functional studies. Neurogastroenterol Motil. 2009;22(4):446-452.

23. Yang CG, Qiu WC, Wang ZG, Yu S, Yan J, Zheng O. Down regulation of ghrelin receptors in the small intestine delay small intestinal transit in vagotomized rats. Mol Med Report. 2011;4(6):1061-1065.

24. Dass NB, Munonyara M, Bassil AK, et al. Growth hormone secretagogue receptors in rat and human gastrointestinal tract and the effects of ghrelin. Neuroscience. 2003;120(2):443-453.
25. Kalff JC, Schraut WH, Simmons RL, Bauer AJ. Surgical manipulation of the gut elicits an intestinal muscularis inflammatory response resulting in postsurgical ileus. Ann Surg. 1998;228(5):652-663.

26. Venkova K, Fraser G, Hoveyda HR, Greenwood-Van Meerveld B. Prokinetic effects of a new ghrelin receptor agonist TZP-101 in a rat model of postoperative ileus. Dig Dis Sci. 2007;52(9):2241-2248.

27. Peeters TL. Potential of ghrelin as a therapeutic approach for gastrointestinal motility disorders. Curr Opin Pharmacol. 2006;6(6):553-558.

28. Jiménez-Reina L, Cañete R, de la Torre MJ, Bernal G. Influence of chronic treatment with the growth hormone secretagogue Ipamorelin, in young female rats: somatotroph response in vitro. Histol Histopathol. 2002;17(3):707-714.

29. Trudel L, Tomasetto C, Rio MC, et al. Ghrelin/motilin-related peptide is a potent prokinetic to reverse gastric postoperative ileus in rat. $\mathrm{Am} \mathrm{J}$ Physiol Gastrointest Liver Physiol. 2002;282(6):G948-G952.

30. Poitras P, Polvino WJ, Rocheleau B. Gastrokinetic effect of ghrelin analog RC-1139 in the rat. Effect on post-operative and on morphine induced ileus. Peptides. 2005;26(9):1598-1601.

31. Chen YT, Tsai SH, Sheu SY, Tsai LH. Ghrelin improves LPS-induced gastrointestinal motility disturbances: role of $\mathrm{NO}$ and prostaglandin $\mathrm{E}_{2}$. Shock. 2010;33(2):205-212
Journal of Experimental Pharmacology

\section{Publish your work in this journal}

The Journal of Experimental Pharmacology is an international, peerreviewed, open access journal publishing original research, reports, reviews and commentaries on all areas of laboratory and experimental pharmacology. The manuscript management system is completely online and includes a very quick and fair peer-review system.

\section{Dovepress}

Visit http://www.dovepress.com/testimonials.php to read real quotes from published authors. 